Article

\title{
Graphene Supported Tungsten Carbide as Catalyst for Electrochemical Reduction of $\mathrm{CO}_{2}$
}

\author{
Sahithi Ananthaneni, Zachery Smith and Rees B. Rankin* \\ Department of Chemical Engineering, Villanova University, 800 E Lancaster University, Villanova, \\ PA 19085, USA \\ * Correspondence: rb.rankin@villanova.edu
}

Received: 14 June 2019; Accepted: 4 July 2019; Published: 15 July 2019

check for updates

\begin{abstract}
Electrochemical reduction of $\mathrm{CO}_{2}$ to useful chemical and fuels in an energy efficient way is currently an expensive and inefficient process. Recently, low-cost transition metal-carbides (TMCs) have been proven to exhibit similar electronic structure similarities to Platinum-Group-Metal (PGM) catalysts and hence, can be good substitutes for some important reduction reactions. In this work, we test graphene-supported WC (Tungsten Carbide) nanoclusters as an electrocatalyst for the $\mathrm{CO}_{2}$ reduction reaction. Specifically, we perform density functional theory (DFT) studies to understand various possible reaction mechanisms and determine the lowest thermodynamic energy landscape of $\mathrm{CO}_{2}$ reduction to various products, such as $\mathrm{CO}, \mathrm{HCOOH}, \mathrm{CH}_{3} \mathrm{OH}$, and $\mathrm{CH}_{4}$. This in-depth study of reaction energetics could lead to improvements and development of more efficient electrocatalysts for $\mathrm{CO}_{2}$ reduction.
\end{abstract}

Keywords: electrochemical reduction; electrocatalyst; energy landscape; $\mathrm{CO}_{2} \mathrm{RR}$; Tungsten Carbide; graphene; DFT

\section{Introduction}

The carbon dioxide $\left(\mathrm{CO}_{2}\right)$ is very stable under environmental conditions, and reduction to some hydrocarbon products is an endothermic (or endergonic) process. The process requires a moderate to highly negative potential combined with excellent catalyst kinetic barrier efficiency to minimize the combined energy barriers for this reduction reaction. Among various methods of $\mathrm{CO}_{2}$ reduction, photocatalytic and electrocatalytic processes are predominantly studied. In the case of electrocatalysis, the reaction rate and products can be controlled by tuning the external potential, whereas the driving force for photocatalysis is solar energy. Although this work does not focus on studying photocatalytic reduction of $\mathrm{CO}_{2}$, it is well worth understanding this process and reduction mechanism while discussing electrochemical $\mathrm{CO}_{2}$ reduction and its state-of-the-art catalysts.

Photocatalysis involves photon absorption by a semiconductor photocatalyst followed by electron-hole pair excitation, charge transfer, and surface (redox) chemistry. The surface reaction pathways in $\mathrm{CO}_{2}$ photocatalytic reduction are similar to electrocatalytic reduction. However, the oxidation and reduction reactions occur on different sides of the catalyst, and the driving force for this process is from solar energy. It still remains as a significant challenge to fabricate a semiconductor photocatalyst which can efficiently separate the electron-hole pairs generated and prevent recombination, transfer electrons to the surface, and provide a catalytic surface for the reaction to occur [1-3]. There have been continuous improvements in design and engineering towards the development of a novel photocatalyst in various ways hoping to overcome the above challenges. Some of them are by:

1. Adjusting bandgap and band position to capture solar energy effectively, thereby improving the efficiency of $\mathrm{CO}_{2}$ reduction. For example, the potential of the valence band of various metal oxide 
catalysts is around $3 \mathrm{eV}$ vs. NHE (normal hydrogen electrode), utilizing only ultraviolet light. Replacing the $\mathrm{O}$ atom with $\mathrm{N}$ or $\mathrm{C}$ will narrow the bandgap thereby efficiently absorbing the solar radiations $[4,5]$.

2. Modifying surface structure and electronic properties by addition of oxygen vacancies, which can lower the energy barrier due to the attraction between $\mathrm{CO}_{2}$ molecules and oxygen vacancy. DFT calculations on $\mathrm{TiO}_{2}$ surface with oxygen vacancies is more effective for $\mathrm{CO}_{2}$ activation than $\mathrm{TiO}_{2}[6,7]$.

3. The use of nanostructured semiconductors in the form of nanorods, nanowires, nanotubes, nanobelts, etc. decreases the electron-hole recombination rate as these are usually in a single crystalline phase that eliminates the possibility of grain boundaries and defects in the materials as they act as recombination sites for the electron-hole pair in polycrystalline materials. At the same time, one-dimensional nanostructures improve electron transport by improving the separation of electron-hole pairs. For instance, $\mathrm{Zn}_{2} \mathrm{GeO}_{4}$ nanoribbons are proven to show improved photocatalytic activity towards $\mathrm{CH}_{4}$ formation when compared to bulk $\mathrm{Zn}_{2} \mathrm{GeO}_{4}[8,9]$

4. Use of co-catalysts in the process to promote the separation and movement of charge carriers. This will minimize the recombination of electron-hole pairs due to the barrier between semiconductor and co-catalyst. Metal nanoparticles, such as $\mathrm{Pt}, \mathrm{Rh}, \mathrm{Pd}, \mathrm{Cu}, \mathrm{Ag}$, $\mathrm{Au}$, supported on semiconductor are proven to work efficiently when compared to pure semiconducting photocatalysts [10,11].

Several electrocatalysts are being studied to convert $\mathrm{CO}_{2}$ to useful chemicals and fuels, but they are either limited by high overpotentials or poor product selectivity. In 1985, Hori et al. reported that $\mathrm{Cu}$ is a unique metal catalyst which can reduce $\mathrm{CO}_{2}$ to hydrocarbons efficiently, and further studies described that a $\mathrm{Cu}$ catalyst could electrochemically reduce $\mathrm{CO}_{2}$ to 16 different products among which $\mathrm{CH}_{4}$ and $\mathrm{C}_{2} \mathrm{H}_{4}$ showed higher current densities but at larger overpotentials of up to $1 \mathrm{~V}$ [12-14]. To overcome this obstacle and make the $\mathrm{CO}_{2}$ reduction reaction more viable, we require more complex and tailored materials than simple, pure transition metals.

Recently, low-cost transition metal-carbides (TMCs) have received special attention as electrocatalysts as they have shown improved catalyst stability, activity, and selectivity when compared to their parent metal/elements $[15,16]$. Formation of carbides (with $C$ in the crystal lattice or nanoparticle surface) modifies the metal-atom bonding, increasing the metal-metal distance, thereby causing a contraction in the metal atoms'd-band. These d-band contractions would give a better density of states near the Fermi level than their parent metal. In particular, non-noble metal-carbides, such as Mo and $\mathrm{W}$, display a similar electronic structure to noble metals due to their metal-covalent binding and hence, can be significant substitutes for precious catalysts in various important catalytic reactions [16]. Additional to electronic and magnetic properties similar to transition metals, they exhibit high melting points as in ionic compounds and hardness similar to covalent solids. Therefore, the bonding in TMCs can be explained as a combination of metallic, covalent, and ionic components [17].

Theoretical and experimental studies proved that TMCs show better catalyst activity in "hydrogen-participating" reactions [18]. For example, metal terminated WC exhibited good activity for hydrogen evolution reaction (HER) and WC coated with Fe when tested for $\mathrm{CO}_{2}$ reduction are selective towards methane formation. This is because electronic properties of $\mathrm{W}$ atoms surrounding Fe are modified, thereby modifying the selectivity. Another interesting phenomenon of TMCs is they do not follow scaling relations that correlate binding energies of intermediates in a reaction network as with other transition metals mainly because of their oxygen affinity, i.e., their tendency to bind carbon-bound species weakly compared to oxygen-bound species. This will open up several possibilities to improve their catalyst activity, selectivity compared to metal catalysts $[19,20]$. In the same way, in the density functional theory (DFT) study of Fe and Co carbides for Fischer-Tropsch synthesis, it was found that $\mathrm{FeC}$ (iron carbide) is more active than pure Fe for $\mathrm{CO}$ hydrogenation and methane selectivity is higher on Co carbide compared to pure Co [21].

Among different metal-carbides, tungsten carbide (WC) based compounds are widely studied electrocatalysts [22]. They are investigated in various forms, such as: 
1. Alloys to combine the electronic properties of WC with other metal(s), for example, Tantalum doped WC displayed better activity towards hydrogen evolution (HER) when compared to unmodified WC [23].

2. The specific shape and structural arrangement, such as core-shell structures of WC with monolayer metal coatings which are stable against $\mathrm{CO}$ poisoning, thereby improving the activity of methanol electro-oxidation [24-27].

3. Catalyst support to increase the electrocatalytic activity leading to better performance of fuel cells, such as WC supported $\mathrm{Pt}$ which is found to be more thermally and electrochemically stable than $\mathrm{Pt} / \mathrm{C}$ for oxygen reduction reaction [28,29].

4. Co-catalyst to the catalytic system where strong electronic interactions between them might modify (maximize) the electrocatalytic activity. As an example, Ni with WC nanocluster for urea electro-oxidation showed high tolerance towards CO poisoning, and high stability thereby enhancing catalyst activity [30].

All these studies explain that TMCs have the potential to work as better catalysts making them an attractive alternative for traditional metallic catalysts in some of the industrially relevant catalytic reactions. Nanocatalysts in the form of nanoclusters where the atoms are structurally quasi-defined to well-defined help in experimental and theoretical investigations of important electronic structure properties in $\mathrm{CO}_{2}$ electroreduction reactions $\left(\mathrm{CO}_{2} \mathrm{RR}\right)$. Additionally, graphene as a catalyst support further improves the active surface area for the catalyst systems by providing a minimal adsorption footprint for the TMC nanoparticles (NP). Other unique properties of this two-dimensional structure, such as high stability and electrical conductivity which can modify the TMC NP electronic structure, help in selectivity and cost reduction of catalysts playing a pivotal role in most of the heterogeneous catalyst systems [31].

Motivated by all the above aspects, in this study, we test graphene supported WC nanocluster as an electrocatalyst for $\mathrm{CO}_{2} \mathrm{RR}$. This work determines the performance of WC/graphene as a catalyst system for $\mathrm{CO}_{2}$ reduction to various products, such as $\mathrm{CO}, \mathrm{HCOOH}, \mathrm{CH}_{3} \mathrm{OH}$, and $\mathrm{CH}_{4}$, which possibly could be the platform for designing new and improved TMC electrocatalysts for this important reduction reaction. To achieve this, we have calculated binding free energies of all possible reaction intermediates and analyzed the reaction mechanisms in detail by focusing on understanding the effect solvation energies on product selectivity and catalyst activity and lastly determined the lowest energy pathways for all the products mentioned above. We inferred that $\mathrm{CH}_{4}$ is favored over $\mathrm{CH}_{3} \mathrm{OH}$ on WC/graphene at lower reducing potentials. From literature, $\mathrm{CH}_{3} \mathrm{OH}$ formation is less preferred on WC and metal-coated WC because of the stronger binding of $\mathrm{O}^{*}$ and $\mathrm{OH}^{*}$ bound species $[20,27,32]$. Results from the current work explain that the reduction to $\mathrm{CH}_{3} \mathrm{OH}$ on graphene supported WC is thermodynamically favorable at higher negative potentials compared to reduction to $\mathrm{CH}_{4}$, which is in qualitative agreement with the results from the literature.

\section{Results and Discussion}

We studied several possible reaction intermediates and plotted free energy diagrams for various possible reaction mechanisms to determine the lowest energy pathway for each product. The stability of these adsorbed species can be determined in terms of the difference in binding free energies between intermediates formed along the reaction pathway and reactants. That is, when the adsorption of an intermediate is unstable ( $\Delta \mathrm{G}$ is positive), the downhill reaction is possible by applying an external potential. Intermediate species with net positive $\Delta \mathrm{G}$ formation in the current study are $\mathrm{COH}^{*}, \mathrm{C}^{*}, \mathrm{CH}^{*}$, $\mathrm{CHOH}^{*}$. At this point, it cannot be decoupled as to how much of this energy is purely attributed to the adsorbed intermediate and how much to the catalyst system. However, as we did not observe any significant changes to the catalyst morphology after adsorption of these intermediates, we assume that contribution to the net positive $\Delta \mathrm{G}$ formation of adsorbed intermediates is mostly due to the net instability or metastability of the adsorbate/intermediate itself relative to the reactant. We expect to 
fully address this area in the follow-up work when we can locate experimental collaboration to further validate the optimization of this catalytic system.

As we apply higher (larger magnitude) negative voltages to different reaction pathways, the pathway with the smallest positive rate-limiting step will be the first pathway to become entirely exergonic across all steps in the pathway. This pathway will be the best lowest energy reaction pathway for $\mathrm{CO}_{2} \mathrm{RR}$. These free energy diagrams (FEDs) provide an overall understanding of the reaction mechanism, electrocatalytic activity for $\mathrm{CO}_{2} \mathrm{RR}$ as well as selectivity of products. Here, we focus on the lowest $\Delta \mathrm{G}$ pathway for $\mathrm{CO}_{2} \mathrm{RR}$ to $\mathrm{CO}, \mathrm{HCOOH}, \mathrm{CH}_{3} \mathrm{OH}$, and $\mathrm{CH}_{4}$.

\section{1. $\mathrm{CO}$ and $\mathrm{HCOOH}$ as Products}

Figures 1 and 2 show the lowest energy pathway for $\mathrm{CO}_{2}$ reduction to $\mathrm{HCOOH}$ and $\mathrm{CO}$ at $0 \mathrm{~V}$ vs. RHE (reversible hydrogen electrode) on graphene supported WC. These products are obtained by two proton-electron transfers along the reaction pathway. $\mathrm{CO}_{2}$ is first protonated to form either $\mathrm{COOH}^{*}$ or $\mathrm{OCHO}^{*}$. The limiting potential for $\mathrm{HCOOH}$ and $\mathrm{CO}$ formation depends on how strongly or weakly $\mathrm{COOH}^{*}$ and $\mathrm{OCHO}^{*}$ bind to the surface. When we compare binding free energies, the formation of $\mathrm{COOH}^{*}$ is less exergonic compared to $\mathrm{OCHO}^{*}$. A second proton-electron transfer results in the formation of $\mathrm{HCOOH}$ and $\mathrm{CO}$. Although $\mathrm{OCHO}^{*}$ is more stable compared to $\mathrm{COOH}^{*}$, the pathway via $\mathrm{COOH}^{*}$ will minimize the rate-limiting step by around $1.9 \mathrm{~V}$ for $\mathrm{HCOOH}$ formation and $2.5 \mathrm{~V}$ for $\mathrm{CO}$ formation. This larger difference in binding free energies of $\mathrm{COOH}^{*}$ and $\mathrm{OCHO}^{*}$ is due to the fact that $\mathrm{COOH}$ tries to bind to the surface of the catalyst via $\mathrm{C}$ and $\mathrm{O}$ atom and $\mathrm{OCHO}$ binds to the surface of the catalyst via two oxygen atoms and $\mathrm{WC}$ has strong oxygen affinity, i.e., it binds $\mathrm{O}^{*}$ and $\mathrm{OH}^{*}$ bound intermediate species very strongly, creating significant energy barriers.

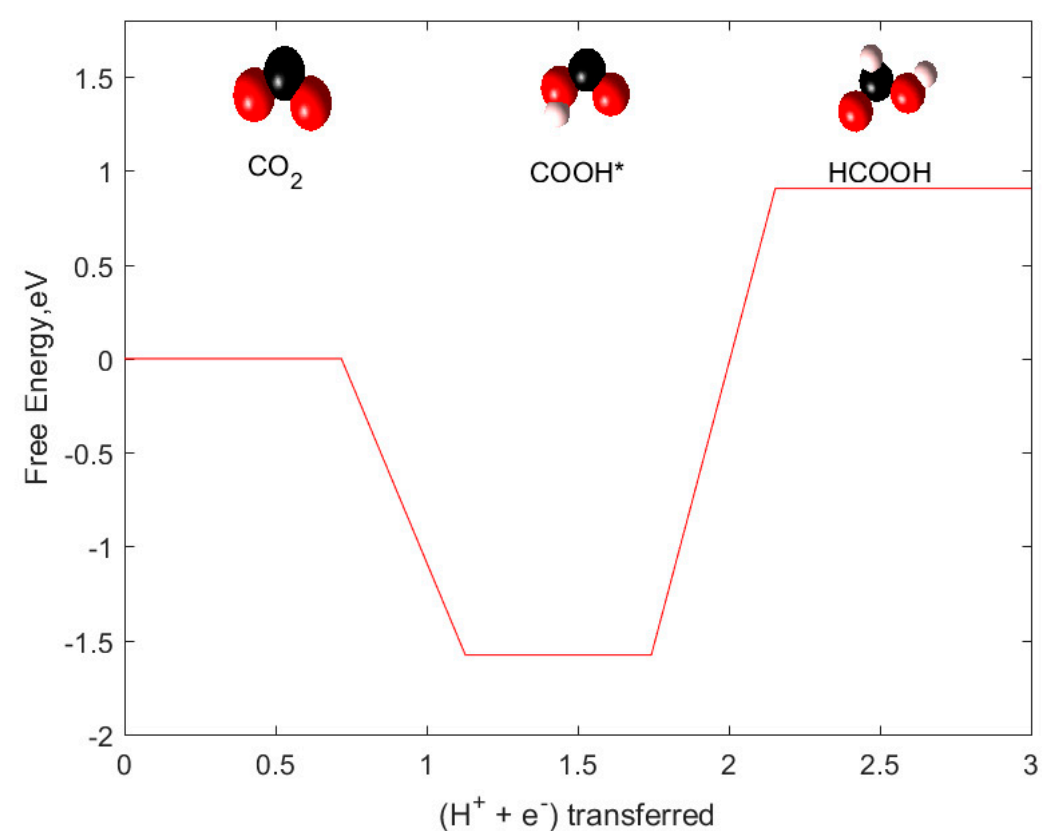

Figure 1. Lowest energy pathway of $\mathrm{CO}_{2}$ reduction to $\mathrm{HCOOH}$ at $\mathrm{U}=0 \mathrm{~V}$ on $\mathrm{WC} /$ graphene. Color code of atoms: red: oxygen, black: carbon, white: hydrogen. 


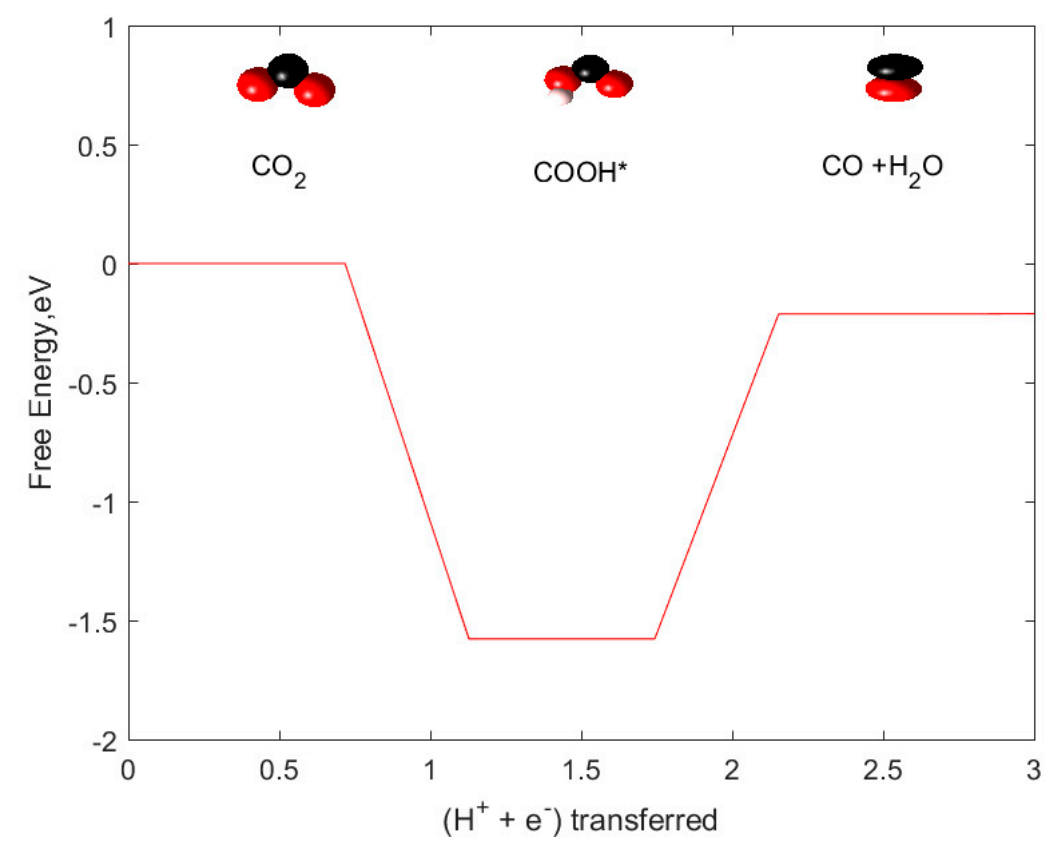

Figure 2. Lowest energy pathway of $\mathrm{CO}_{2}$ reduction to $\mathrm{CO}$ at $\mathrm{U}=0 \mathrm{~V}$ on $\mathrm{WC} /$ graphene. Color code of atoms: red: oxygen, black: carbon, white: hydrogen.

Figure 1 shows the lowest energy pathway for $\mathrm{HCOOH}$ formation. The calculated limiting potential for $\mathrm{HCOOH}$ formation is $-2.45 \mathrm{~V}$, and the potential determining step, i.e., the rate-limiting step is the formation of $\mathrm{HCOOH}$ from $\mathrm{COOH}^{*}$. Figure 2 shows the lowest energy pathway for $\mathrm{CO}$ formation. The calculated limiting potential for $\mathrm{CO}$ formation is $-1.36 \mathrm{~V}$, and the rate-limiting step is the formation of $\mathrm{CO}$ from $\mathrm{COOH}^{*}$. This is in agreement with previous experimental and theoretical studies showing the reduction potential for $\mathrm{CO}_{2}$ to $\mathrm{CO}$ is in the range of $-0.72 \mathrm{~V}$ to $-1.5 \mathrm{~V}$ on pure metal surfaces, such as $\mathrm{Ag}, \mathrm{Au}, \mathrm{Zn}$. This comparison also confirms that $\mathrm{WC} /$ graphene can be used as an alternative for precious electrocatalysts for $\mathrm{CO}_{2}$ reduction to $\mathrm{CO}$. Further reduction of $\mathrm{CO}^{*}$ to $\mathrm{CH}_{3} \mathrm{OH}$ and $\mathrm{CH}_{4}$ as products is determined by the binding energy of $\mathrm{CO}^{*}$. Stronger binding of $\mathrm{CO}^{*}$ results in hydrogen evolution due to $\mathrm{CO}$ poisoning and weaker binding of $\mathrm{CO}^{*}$ results in $\mathrm{CO}$ desorption before further reduction to products. It is proven from previous work that metals, such as $\mathrm{Ag}$, $\mathrm{Au}$, and $\mathrm{Zn}$, that bind $\mathrm{CO}$ weakly during $\mathrm{CO}_{2}$ reduction can further reduce to $\mathrm{CH}_{3} \mathrm{OH}$ and $\mathrm{CH}_{4}$ but at higher negative potentials. Therefore, in the next section, we will discuss $\mathrm{CO}_{2}$ reduction to $\mathrm{CH}_{3} \mathrm{OH}$ and $\mathrm{CH}_{4}$ on graphene supported WC.

\section{2. $\mathrm{CH}_{3} \mathrm{OH}$ and $\mathrm{CH}_{4}$ as Products}

This section discusses the lowest energy pathways for $\mathrm{CO}_{2}$ reduction to $\mathrm{CH}_{3} \mathrm{OH}$ and $\mathrm{CH}_{4}$ at $0 \mathrm{~V}$ on graphene supported WC. These products are obtained by six and eight proton-electron transfers, respectively, along the reaction pathway. The first two steps up to $\mathrm{CO}^{*}$ formation are described in detail in the previous section. However, complexity arises when $\mathrm{CO}^{*}$ is further protonated. As the number of protons-electrons transferred increase, the number of required intermediates in each reaction network increases. This is one of the reasons why the $\mathrm{CO}_{2}$ electrochemical reduction reaction mechanism and its thermodynamics is more complex to study when compared to oxygen reduction reaction (ORR), hydrogen evolution reaction (HER), and other reactions involving the transfer of fewer proton-electron pairs. Similar to $\mathrm{CO}$ and $\mathrm{HCOOH}$ formation, $\mathrm{CH}_{3} \mathrm{OH}$ and $\mathrm{CH}_{4}$ product formation follow a reaction pathway via $\mathrm{COOH}^{*}$. The protonation of $\mathrm{CO}^{*}$ in electrochemical reduction to $\mathrm{CH}_{3} \mathrm{OH}$ and $\mathrm{CH}_{4}$ can follow either an oxophilic pathway $\left(\mathrm{CO}^{*}\right.$ is protonated at $\mathrm{C}$ atom to form $\mathrm{HCO}^{*}$ and binds to the surface of the catalyst via $\mathrm{O}$ atom) or a carbophilic pathway $\left(\mathrm{CO}^{*}\right.$ is protonated at $\mathrm{O}$ atom to form $\mathrm{COH}^{*}$ and binds to the surface of the catalyst via $\mathrm{C}$ atom). 


\section{3. $\mathrm{CH}_{3} \mathrm{OH}$ as Product}

Figures 3 and 4 display the lowest energy pathway for $\mathrm{CH}_{3} \mathrm{OH}$ formation with and without taking solvation energies into account. Apart from the reaction mechanism, these free energy diagrams also guide us in understanding the effect of solvation on the reaction thermodynamics in $\mathrm{CH}_{3} \mathrm{OH}$ formation. In Figure 3, we have shown the lowest energy pathway for $\mathrm{CH}_{3} \mathrm{OH}$ formation when solvation energies are excluded. Real aqueous phase electrochemical $\mathrm{CO}_{2} \mathrm{RR}$ has water molecules present around the TMC NP, and these water molecules can stabilize the reactants, products, and intermediates through $\mathrm{H}$-bonding. The protonation of $\mathrm{CO}^{*}$ in this product formation is via the oxophilic pathway, i.e., via $\mathrm{HCO}^{*}$ species. If the solvation effect is not considered, the calculated limiting potential for the product formation is $-0.56 \mathrm{~V}$ with the rate-limiting step of $\mathrm{CH}_{3} \mathrm{O}^{*}$ to $\mathrm{CH}_{3} \mathrm{OH}$ formation. Figure 4 shows the lowest energy pathway with the addition of solvation energies. Inclusion of solvation energies in electrochemical reduction to $\mathrm{CH}_{3} \mathrm{OH}$ modified not only the reducing potential but also the lowest energy reaction pathway and the rate-limiting step. The limiting potential is increased from -0.56 $\mathrm{V}$ to $-1.79 \mathrm{~V}$, and the reaction pathway is shifted from an oxophilic to the carbophilic pathway, i.e., the pathway is shifted from $\mathrm{HCO}^{*}$ to $\mathrm{COH}^{*}$. The new rate-limiting step is the formation of $\mathrm{CHOH}^{*}$ from $\mathrm{COH}^{*}$. It is worth noting that these changes in the reaction pathway, rate-limiting step, and its corresponding potential is due to the following reason: WC has strong oxygen affinity; therefore, it strongly binds all $\mathrm{O}^{*}$ and $\mathrm{OH}^{*}$ bound intermediate species. Inclusion of the solvent effect has further stabilized these $\mathrm{O}^{*}$, and $\mathrm{OH}^{*}$ bound intermediate species altering the electronic binding free energies, thereby creating huge energy barriers in the reaction network.

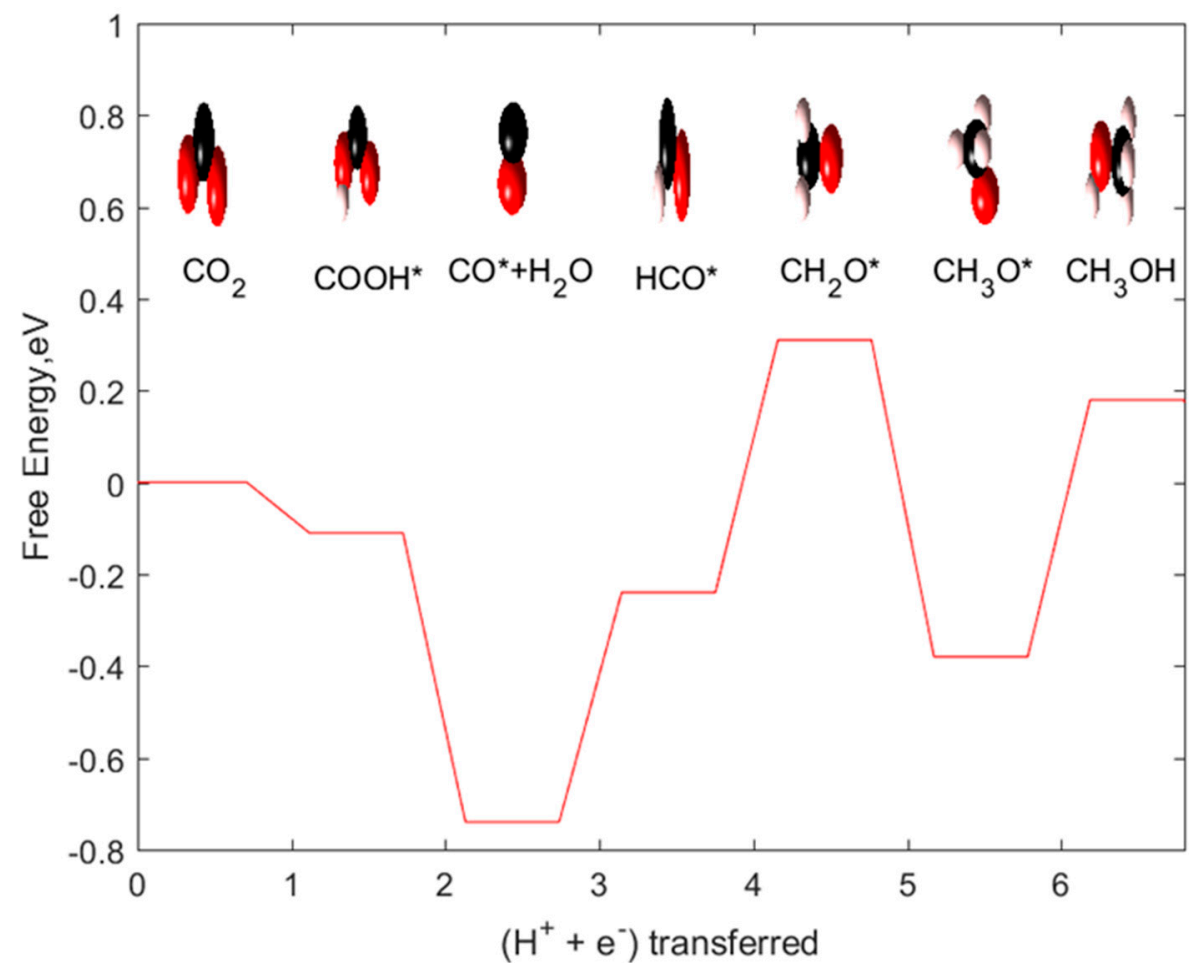

Figure 3. Lowest energy pathway of $\mathrm{CO}_{2}$ reduction to $\mathrm{CH}_{3} \mathrm{OH}$ on the $\mathrm{WC} /$ graphene excluding solvation effect. Color code of atoms: red: oxygen, black: carbon, white: hydrogen. 


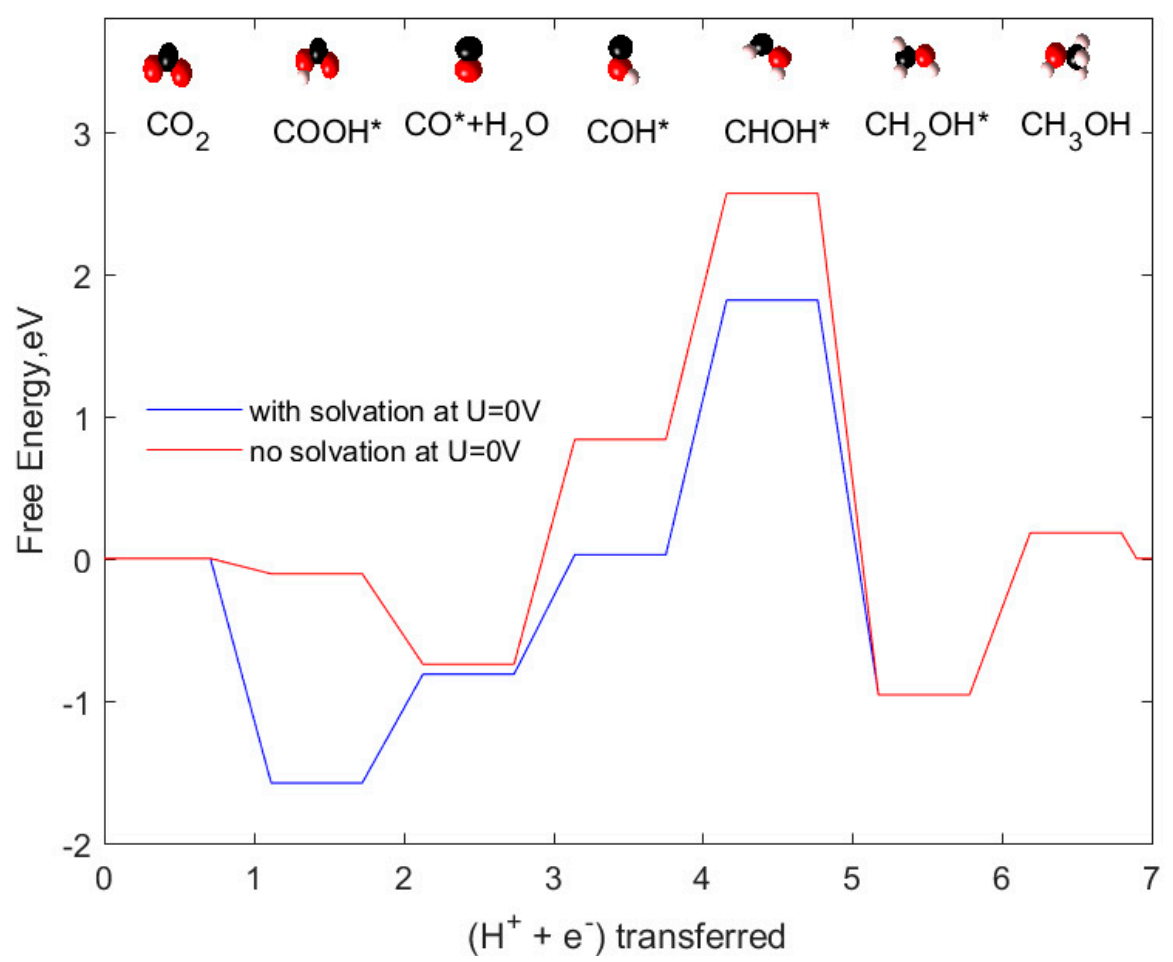

Figure 4. Lowest energy pathways of $\mathrm{CO}_{2}$ reduction to $\mathrm{CH}_{3} \mathrm{OH}$ on the $\mathrm{WC} /$ graphene. Blue pathway: including solvation energy correction factor. Red pathway: without solvation energy correction factor. Color code of atoms: red: oxygen, black: carbon, white: hydrogen.

For additional comparison, in Figure 4, we have included the carbophilic pathway without solvation energies (red pathway). The calculated limiting potential for the product formation is $-1.73 \mathrm{~V}$ with rate-limiting step $\mathrm{COH}^{*}$ to $\mathrm{CHOH}^{*}$. Inclusion of solvation energies (blue pathway) has stabilized the adsorbate species and minimized the reducing potential by $\sim 0.06 \mathrm{~V}$ without modifying the rate-limiting step of the carbophilic pathway.

\section{4. $\mathrm{CH}_{4}$ as Product}

Figure 5, red pathway, shows the lowest energy pathway without the solvation energy correction factor and the calculated limiting potential for the $\mathrm{CH}_{4}$ formation is $-1.58 \mathrm{~V}$ with the same rate-limiting step, i.e., $\mathrm{CO}^{*}$ to $\mathrm{COH}^{*}$. The blue pathway is the lowest energy pathway after adding the solvation correction factor and the calculated limiting potential for product formation is $-0.84 \mathrm{~V}$, and the rate-limiting step is the formation of $\mathrm{CO}^{*}$ from $\mathrm{COH}^{*}$. The key point here is the inclusion of solvation energies minimized the reducing potential by around $0.75 \mathrm{~V}$ but did not modify the lowest energy reaction pathway. This may be due to the fact that $\mathrm{CH}_{4}$ formation pathway is via the carbophilic pathway and carbon bound species. Therefore, the effect of solvation stabilized the $\mathrm{COOH}^{*}, \mathrm{CO}^{*}$, and $\mathrm{COH}^{*}$ binding free energies modifying just the first four steps in the reaction pathway.

Figures 6 and 7 show the calculated lowest energy profiles, including solvation energies for a complete series of elementary steps leading to $\mathrm{CH}_{3} \mathrm{OH}$ and $\mathrm{CH}_{4}$ formation, respectively. We have also included the free energy profile of product formation at the thermodynamic limiting potential/reducing potential, i.e., the potential at which all the elementary steps are downhill (exergonic) in free energy. This is used to determine the overpotentials of the reaction on a particular electrocatalyst.

Overpotentials can be directly related to the catalyst activity and energy efficiency and can be obtained by the difference between the equilibrium potential and limiting potential. On our catalyst system, $\mathrm{CO}_{2}$ can reduce to $\mathrm{CH}_{3} \mathrm{OH}$ with an overpotential of $1.81 \mathrm{~V}$ and $\mathrm{CH}_{4}$ with an overpotential of $0.67 \mathrm{~V}$. For additional comparison we have shown free energy profile at the equilibrium potentials, and the maximum potential allowed by the thermodynamics. 


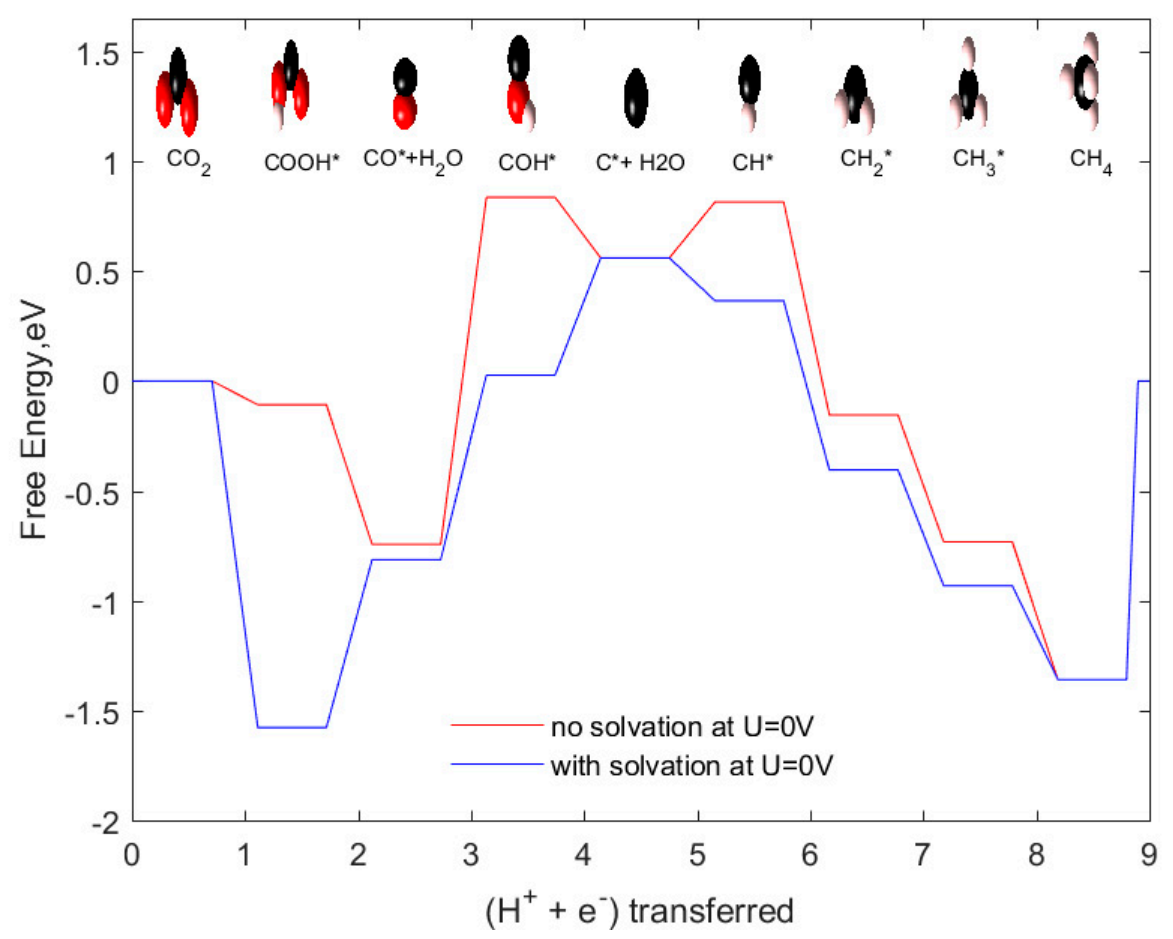

Figure 5. Lowest energy pathway of $\mathrm{CO}_{2}$ reduction to $\mathrm{CH}_{4}$ on the $\mathrm{WC} /$ graphene. Red: excluding the solvation effect. Blue: including solvation effect. Color code of atoms: red: oxygen, black: carbon, white: hydrogen.

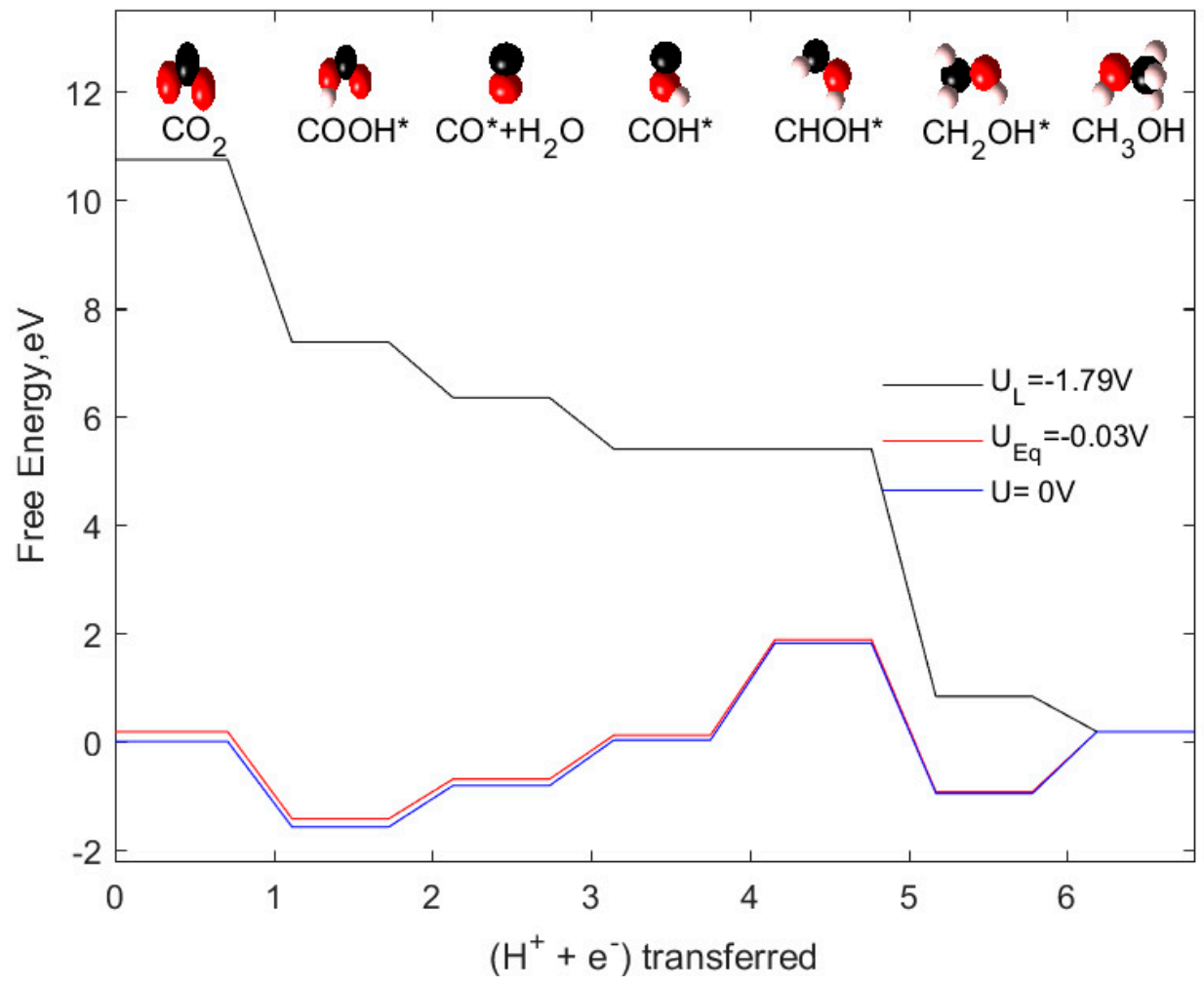

Figure 6. Reaction energy profiles for $\mathrm{CO}_{2}$ reduction to $\mathrm{CH}_{3} \mathrm{OH}$ at $0 \mathrm{~V}$ vs. $\mathrm{RHE}$ (blue), thermodynamic limiting potential of (UL) $-1.79 \mathrm{~V}$ vs. RHE (black) and equilibrium potential (UE) of $-0.03 \mathrm{~V}$ vs. RHE (red). Color code of atoms: red: oxygen, black: carbon, white: hydrogen. 


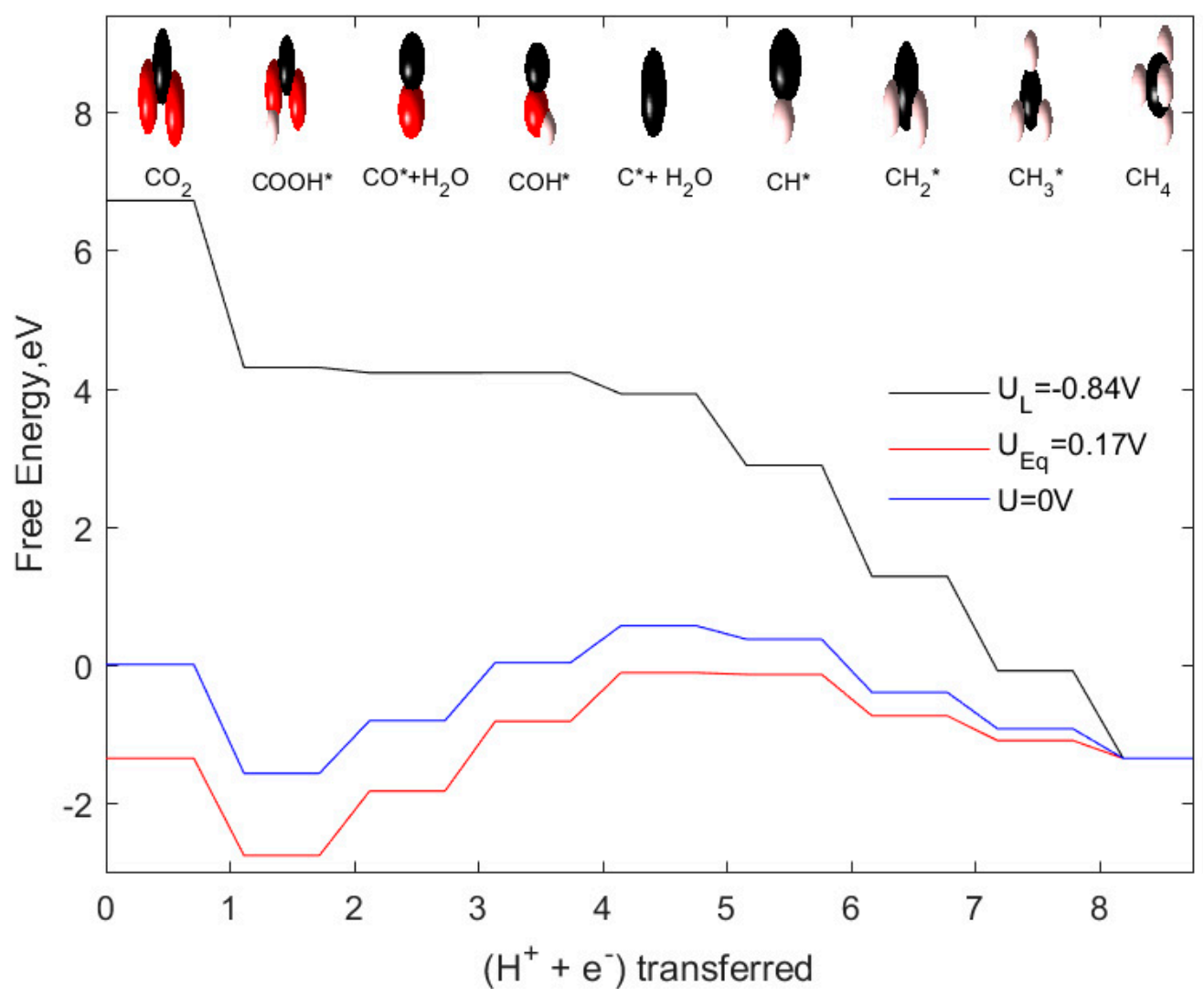

Figure 7. Reaction energy profiles for $\mathrm{CO}_{2}$ reduction to $\mathrm{CH}_{4}$ at $0 \mathrm{~V}$ vs. $\mathrm{RHE}$ (blue), thermodynamic limiting potential $\left(\mathrm{U}_{\mathrm{L}}\right)$ of $-0.84 \mathrm{~V}$ vs. RHE (black) and equilibrium potential $\left(\mathrm{U}_{\mathrm{E}}\right)$ of $0.17 \mathrm{~V}$ vs. RHE (red). Color code of atoms: red: oxygen, black: carbon, white: hydrogen.

\subsection{Comparison of $\mathrm{CO}_{2}$ Reduction to $\mathrm{CH}_{4}$ and $\mathrm{CH}_{3} \mathrm{OH}$ on Graphene Supported WC Nanocluster and} WC (0001)

In this section, we compare $\mathrm{CO}_{2}$ reduction on $\mathrm{WC} /$ graphene to that on $\mathrm{WC}(0001)$. Our analysis and comparison are based on the reaction free energy profile. From the work of Wannakao S. et al., the limiting potential for $\mathrm{CO}_{2}$ reduction to $\mathrm{CH}_{4}$ on $\mathrm{WC}(0001)$ is $-0.35 \mathrm{~V}$ (no solvation) which is $0.5 \mathrm{~V}$ (with solvation) lower than the potential achieved in the current work. Similarly, the limiting potential for $\mathrm{CH}_{3} \mathrm{OH}$ formation on WC (0001) is around $-0.39 \mathrm{~V}$ (no solvation), which is around $1.5 \mathrm{~V}$ (with solvation) lower than the potential achieved in the current work. This difference in potential could be due to the following reasons:

1. Employing different functionals in the DFT calculations would result in differences in binding free energies of intermediates. In the work of Wannakao S. et al., it is proven that

2. Another reason is predicted to be due to the coverage of adsorbed intermediates on the surface of the catalyst. Our catalyst system is designed by placing only one adsorbate species on a single nanocluster which is approximately equal to $1 / 6$ or $1 / 9$ monolayer (ML) coverage of adsorbate species on the surface (assuming each side of the cluster mimics $3 \times 2$ or $3 \times 3$ slab surface). However, in the work of Wannakao S. et al., WC (0001) was modeled by $1 / 6$ to 1/9 ML coverage of adsorbate species which means these are placed comparatively closer than our adsorbate species arrangement. We predict that the influence of lateral interactions between adsorbed intermediates could also lead to a difference in reaction free energies. To investigate this, we vary (increase) the surface coverage of intermediate species by placing two species instead of one in our catalyst system as neighboring atoms/moieties near the active site. In other words, this system is modified to try to approximate the effects of $1 / 6$ to $1 / 9 \mathrm{ML}$ coverage of adsorbate species in their work. Figure 8 shows how the reaction free energies vary when the proportion of adsorbate coverage 
on the catalyst system varies. Here, we have computed the free energies of initial steps in the reaction network $\left(\mathrm{COOH}^{*}, \mathrm{CO}^{*}, \mathrm{COH}^{*}\right)$ as these are the pathway determining intermediates. Co-adsorption of these species generated an upward shift of binding free energies of all the initial three steps. Consequently, the rate-limiting step in the case of co-adsorbed species shifted to the $\mathrm{COOH}^{*}$ protonation step from the $\mathrm{CO}^{*}$ protonation step. This analysis also explains that the surface coverage of the adsorbed species plays an equally important role in determining the energetics of $\mathrm{CO}_{2}$ reduction reaction.

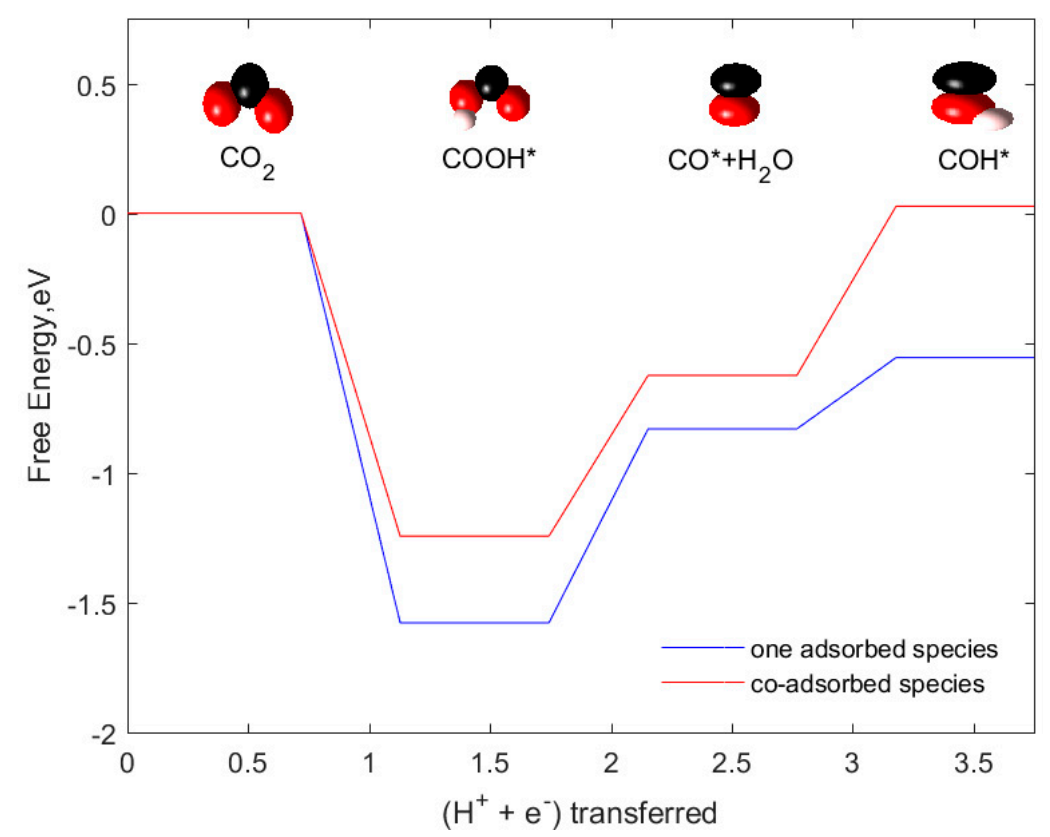

Figure 8. Role of surface coverage on reaction energetics. Blue: one adsorbed species per WC/graphene catalyst system. Red: Co-adsorbed species per WC/graphene catalyst system. Color code of atoms: red: oxygen, black: carbon, white: hydrogen.

\subsection{Role of Graphene}

In the WC-graphene system, the energy barrier of the rate-limiting step is $0.85 \mathrm{~V}$, whereas the energy barrier of the rate-limiting step for the WC nanocluster is $1.04 \mathrm{~V}$. In other words, $\mathrm{CO}^{*}$ and $\mathrm{COH}^{*}$ are further stabilized on graphene supported WC. Therefore, graphene as a support for WC catalyst enhances the energy efficiency of $\mathrm{CO}_{2}$ reduction reaction by lowering the limiting potential by $\sim 0.2 \mathrm{~V}$. Figure 9 compares the free energies of initial steps in the reaction network $\left(\mathrm{COOH}^{*}, \mathrm{CO}^{*}, \mathrm{COH}^{*}\right)$ on graphene supported WC and plain WC nanocluster. Therefore, instead of a numerical comparison of binding free energies and reduction potentials on graphene supported WC and WC (0001), we have compared the reaction pathways and potential determining steps. We have graphically represented the reaction pathways of $\mathrm{CH}_{4}$ formation on WC/graphene and WC (0001) in Figure 10 to show the similarities between them.

From literature, $\mathrm{CH}_{4}$ formation on WC (0001) follows a reaction pathway via $\mathrm{COOH}^{*}$ and $\mathrm{COH}^{*}$ with $\mathrm{CO}^{*}$ protonation to $\mathrm{COH}^{*}$ as the potential determining step. Similarly, current work shows that the lowest energy pathway for $\mathrm{CO}_{2}$ reduction follows the carbophilic pathway with an identical rate-limiting step and binding site (binds to $\mathrm{W}$ through $\mathrm{C}$ from $\mathrm{COH}^{*}$ ). In addition, while comparing $\mathrm{COH}^{*}$ and $\mathrm{HCO}^{*}$ binding energies, both on WC/graphene and $\mathrm{WC}(0001), \mathrm{HCO}^{*}$ (via $\mathrm{C}$ and $\mathrm{O}$ atoms) binds more strongly than $\mathrm{COH}^{*}$ (via $\mathrm{C}$ atom) and in both the cases' pathway via $\mathrm{COH}^{*}$ minimizes the reducing potential when compared to $\mathrm{HCO}^{*}$. 


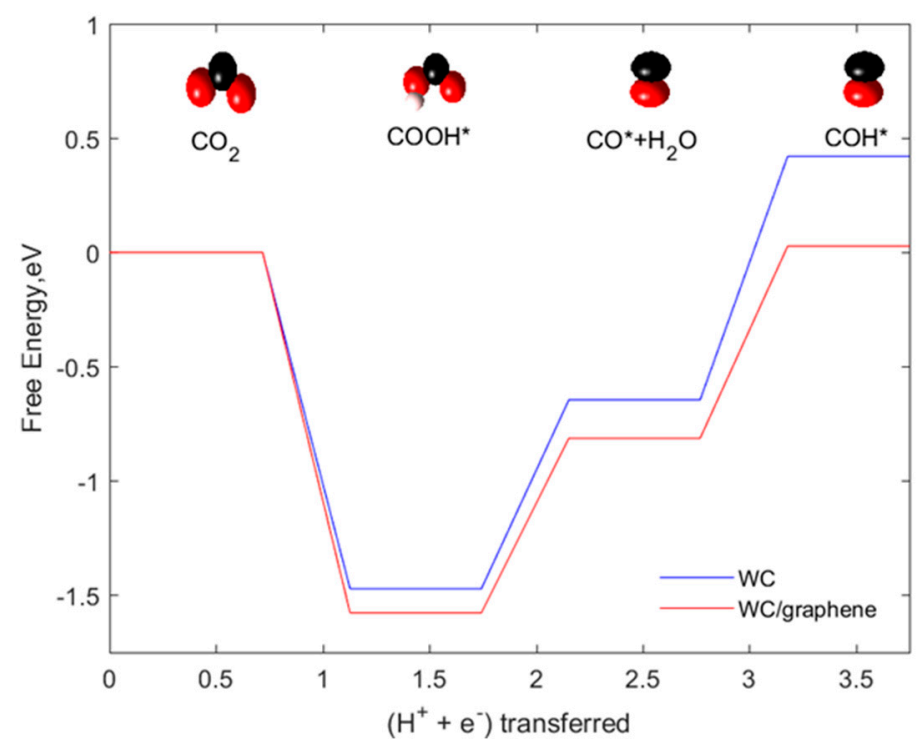

Figure 9. Comparison of reaction energetics of $\mathrm{CO}_{2}$ reduction on WC nanocluster (blue) and graphene supported WC nanocluster (red). Color code of atoms: red: oxygen, black: carbon, white: hydrogen.

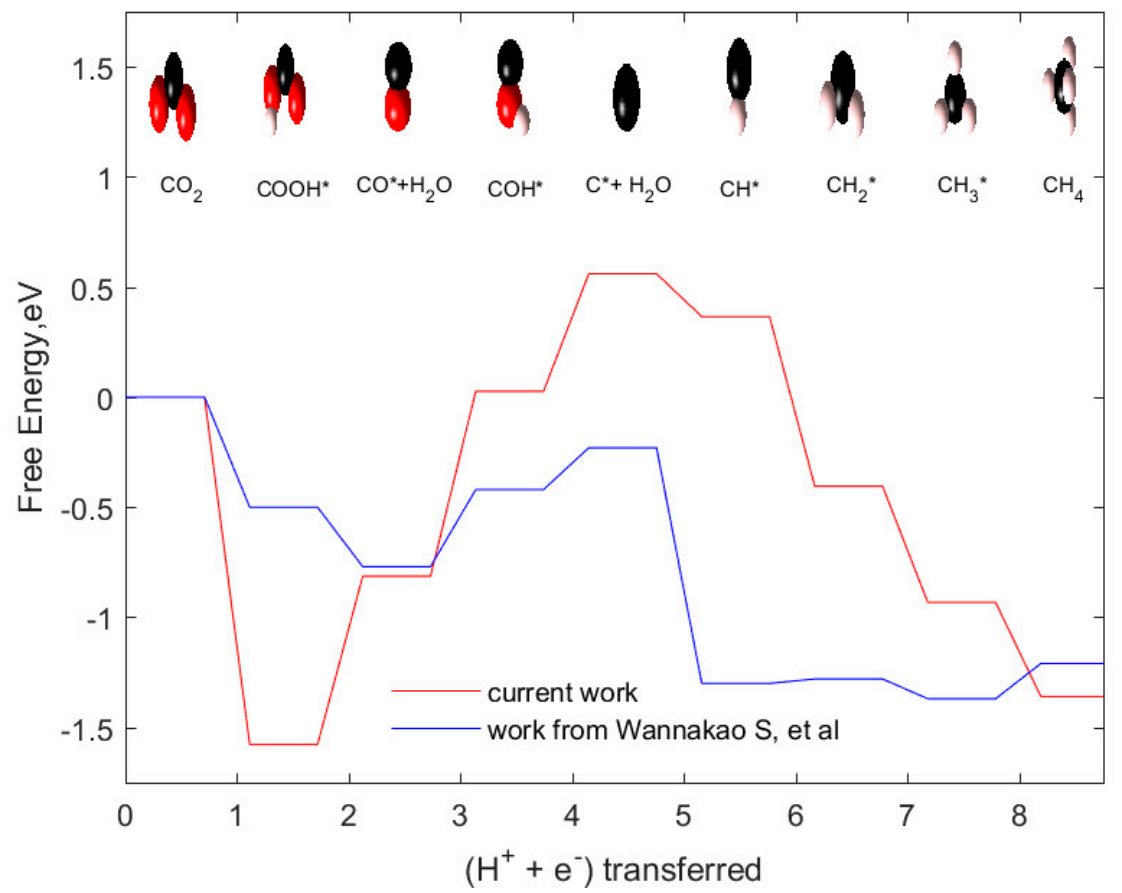

Figure 10. Lowest energy pathway for $\mathrm{CO}_{2}$ reduction to $\mathrm{CH}_{4}$. Red: on graphene supported WC. Blue: on WC (0001) from the work of Wannakao S. et al. Color code of atoms: red: oxygen, black: carbon, white: hydrogen.

\subsection{HER}

There are various studies explaining that the catalysts for $\mathrm{CO}_{2}$ electrochemical reduction are also good catalysts for HER as thermodynamically both HER and $\mathrm{CO}_{2}$ RR require approximately $0 \mathrm{~V}$ (RHE) for the reaction to take place and this is one of the major challenges in $\mathrm{CO}_{2} \mathrm{RR}$. As HER is an unwanted side reaction, we need to design a catalyst which can suppress this reaction and further reduce $\mathrm{CO}_{2}$ to various products. Hence, in this study, we have considered understanding HER in parallel. This is a straightforward reaction where 2 proton electrons are required to form $\mathrm{H}_{2}$. This is a two-step mechanism, and the lowest energy reaction pathway at $\mathrm{U}=0 \mathrm{~V}$ is shown in Figure 11. The limiting 
potential required for HER to take place is $-0.98 \mathrm{~V}$, which is higher than the limiting potential required to form $\mathrm{CH}_{4}$. A recent theoretical study explained that $\mathrm{CO}^{*}$ formed along the $\mathrm{CO}_{2}$ reduction can occupy the adsorption sites preventing $\mathrm{H}^{*}$ contact to the surface and eventually $\mathrm{H}_{2}$ formation [33].

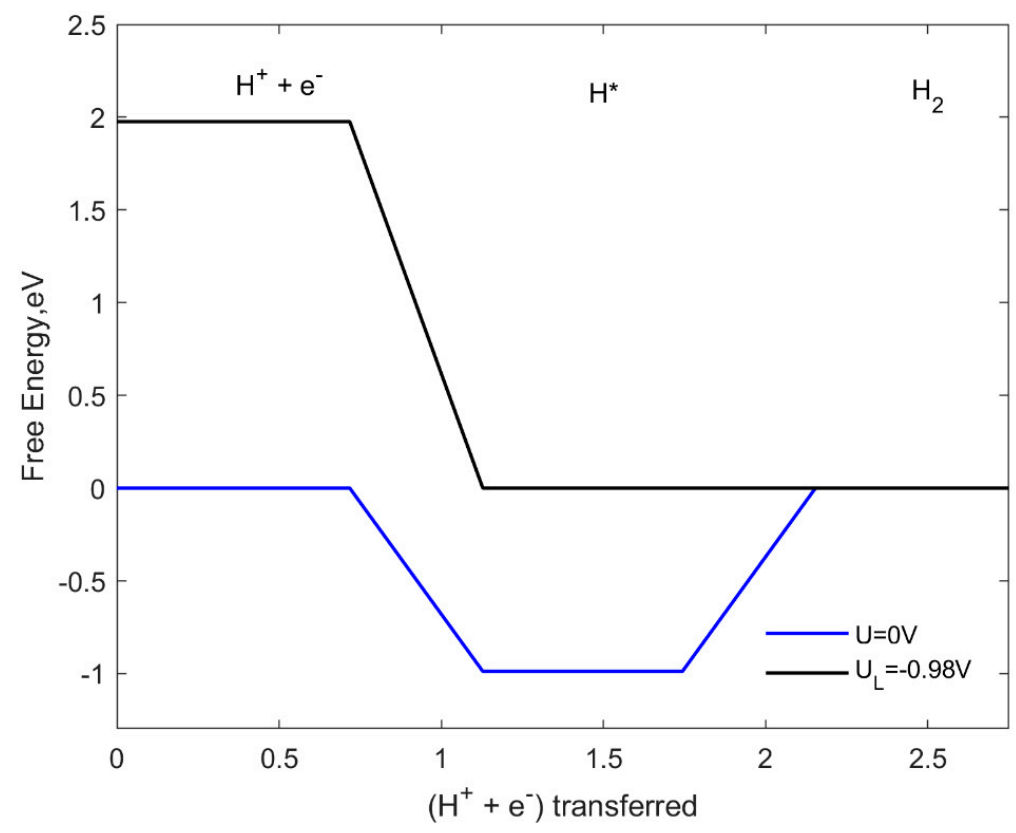

Figure 11. Reaction energy profiles for hydrogen evolution reaction (HER) at $0 \mathrm{~V}$ vs. RHE (blue), thermodynamic limiting potential of (UL) $-0.98 \mathrm{~V}$ vs. RHE (black).

To further understand if WC/graphene system favors HER or $\mathrm{CO}_{2} \mathrm{RR}$ or both, we have compared binding free energies of $\mathrm{H}^{*}$ and $\mathrm{CO}^{*}$ at a range of applied potentials (from $0 \mathrm{~V}$ to $1 \mathrm{~V}$ vs. RHE) as shown in Figure 12. At the range of potentials studied, $\mathrm{CO}^{*}$ formation is thermodynamically more preferred than $\mathrm{H}^{*}$ formation at higher negative potentials. In other words, $\mathrm{CO}^{*}$ becomes more stable (higher negative binding free energy) than $\mathrm{H}^{*}$ at higher negative potentials preventing HER and at the same time opening up pathways for further reduction to products with $\mathrm{C}-\mathrm{H}$ bonds.

$\mathrm{H}^{*}$ vs. $\mathrm{CO}^{*}$ Binding Free Energies

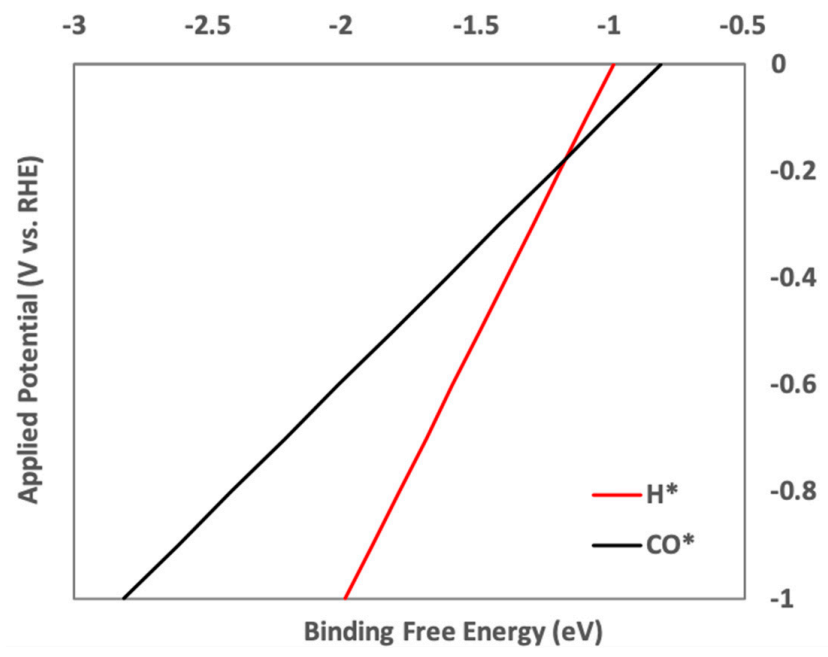

Figure 12. Comparison of adsorption/binding free energies of formation of $\mathrm{H}^{*}$ and $\mathrm{CO}^{*}$ on $\mathrm{WC} / G$ raphene catalyst system at various applied potentials ranging from 0 to $1 \mathrm{~V}$ vs. RHE. Red: $\mathrm{H}^{*}$ binding free energies Black: $\mathrm{CO}^{*}$ binding free energies. 


\section{3. (Computational) Materials and Methods}

We used density functional theory (DFT) to understand catalyst surface reaction pathways in detail. We performed plane wave DFT calculations with VASP (Vienna Ab Initio Simulation Package) to find optimized surface structures and calculate electronic structure properties, such as ground state energies, binding energies, charge densities, and perform Bader charge analysis [34-38]. Throughout this work, all the electronic structure calculations were performed using Van Der Waals, opt-PBE functional as they are proven to show high accuracy to study adsorption properties [38-40]. A Fermi smearing of $0.2 \mathrm{eV}$ is used, and calculations were performed with gamma centered k-points mesh of $2 \times 2 \times 1$ with a convergence of ground state energies up to $10-5 \mathrm{eV} / \mathrm{mol}-$-unit cell with respect to k-point sampling [41]. A vacuum space of $12 \AA$ was defined to minimize the interactions between repeated structures in the direction parallel to the surface normal of the graphene plane. All the reaction energy calculations were completed using the lowest energy conformation of the intermediate species. Detailed images of the structure and some adsorbate snapshots are provided in the Supporting Information (Figure S1) submitted with this manuscript. We took advantage of the computational hydrogen electrode (CHE) approach for screening and designing electrocatalysts primarily to understand reaction mechanisms for $\mathrm{CO}_{2}$ electroreduction to $\mathrm{CH}_{4}$ and $\mathrm{CH}_{3} \mathrm{OH}$ [42-44]. Possible reaction pathways for electrochemical reduction of $\mathrm{CO}_{2}$ to $\mathrm{CO}, \mathrm{CH}_{4}$, and $\mathrm{CH}_{3} \mathrm{OH}$ are shown in Figure 13. We used RHE (reversible hydrogen electrode) as a reference electrode throughout this work. Since RHE is the reference for all the reactions, it can be set to zero.

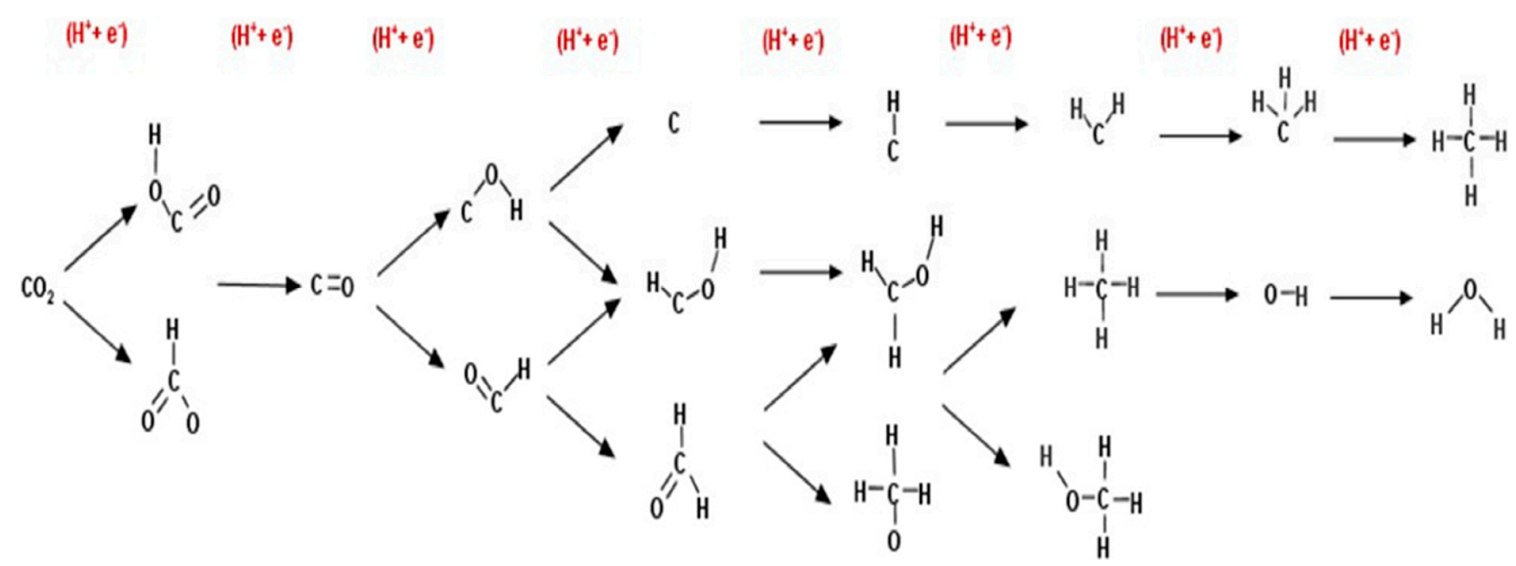

Figure 13. Possible reaction energy mechanisms for electrochemical reduction of $\mathrm{CO}_{2}$ to $\mathrm{CO}, \mathrm{CH}_{4}$, and $\mathrm{CH}_{3} \mathrm{OH}$. OH, and $\mathrm{H}_{2} \mathrm{O}$ formed along the reaction pathways are omitted in the figure for clarity.

The overall reactions of $\mathrm{CO}_{2}$ reduction to products and their corresponding thermodynamic equilibrium potentials are shown in Table 1 below.

Table 1. Overall reactions for $\mathrm{CO}_{2}$ reduction to different products and their equilibrium potentials (U, V vs. RHE) [45].

\begin{tabular}{lc}
\hline \multicolumn{1}{c}{ Reaction } & U (V vs. RHE) \\
\hline $2\left(\mathrm{H}^{+}+\mathrm{e}^{-}\right) \rightarrow \mathrm{H}_{2}$ & 0 \\
$\mathrm{CO}_{2}+2(\mathrm{H}++e-) \rightarrow \mathrm{CO}+\mathrm{H}_{2} \mathrm{O}$ & -0.10 \\
$\mathrm{CO}_{2}+2(\mathrm{H}++e-) \rightarrow \mathrm{HCOOH}$ & -0.20 \\
$\mathrm{CO}_{2}+6(\mathrm{H}++e-) \rightarrow \mathrm{CH}_{3} \mathrm{OH}+\mathrm{H}_{2} \mathrm{O}$ & -0.03 \\
$\mathrm{CO}_{2}+8(\mathrm{H}++e-) \rightarrow \mathrm{CH}_{4}+\mathrm{H}_{2} \mathrm{O}$ & 0.17 \\
\hline
\end{tabular}

The Binding energy of each intermediate species in the reaction network can be calculated using Equation (1). This is the difference between the DFT energy of the adsorbed intermediate and the sum 
of the DFT energy of the bare surface and the formation energies of $\mathrm{C}, \mathrm{H}, \mathrm{O}$ w.r.t gaseous $\mathrm{CO}, \mathrm{H}_{2}$, and $\mathrm{H}_{2} \mathrm{O}$, where $\mathrm{x}, \mathrm{y}$, and $\mathrm{z}$ denote stoichiometries of each element.

$$
\Delta \mathrm{E}_{\text {binding }}=\mathrm{E}_{\mathrm{DFT}}-\left(\mathrm{E}_{\text {surface }}+x \mathrm{E}_{\mathrm{C}}+y \mathrm{E}_{\mathrm{H}}+z \mathrm{E}_{\mathrm{O}}\right)
$$

Similarly, the free energy of each electrochemical step in the reaction pathway corrected by zero-point energies (ZPE) with enthalpy and entropy contributions at potentials other than $0 \mathrm{~V}$ can be estimated using Equation (2) given below.

$$
\Delta \mathrm{G}(\mathrm{U})=\Delta \mathrm{E}_{\mathrm{rxn}}+\Delta \mathrm{ZPE}+\int C_{\mathrm{p}} \mathrm{dT}-\mathrm{T} \Delta \mathrm{S}-\mathrm{neU}
$$

$\mathrm{U}$ is the applied potential to make the elementary step exergonic (known as the limiting potential, $\mathrm{U}_{L}$ ) and $\mathrm{n}$ is the number of proton-electron pairs consumed in each step. The ZPE, enthalpy, and entropy of adsorbed species are obtained from previously determined values as they are assumed to be largely independent of catalyst surface and therefore can be approximated to be the same for all structures [42,46]. Since an explicit treatment of a number of water molecules is tedious to carry out using DFT methods, we have used the implicit method in VASP with the default dielectric constant of $\mathrm{H}_{2} \mathrm{O}$ to calculate solvation energies. These are generally much less computationally demanding than explicit methods but can reproduce significant results as with explicit methods for $\mathrm{O}^{*}, \mathrm{OH}^{*}$ bound intermediate species $[47,48]$.

\section{Conclusions and Future Work}

This work provides theoretical evidence that graphene supported WC nanoparticles could be a useful catalyst system for $\mathrm{CO}_{2}$ reduction to light hydrocarbons and fuels. We have presented an improved understanding of $\mathrm{CO}_{2}$ reduction reaction mechanisms and provided the lowest energy pathway for various products. The results imply that $\mathrm{CH}_{4}$ is favored over $\mathrm{CH}_{3} \mathrm{OH}$ on this catalyst system because of the strong oxygen affinity towards WC. It is also worth noting that the solvation effect plays an important role in determining the reaction pathway. We have shown how the addition of the solvation effect has shifted the rate-limiting step from $\mathrm{CH}_{3} \mathrm{OH}$ formation step to the $\mathrm{COH}^{*}$ protonation step on the lowest energy pathway for $\mathrm{CO}_{2}$ reduction to $\mathrm{CH}_{3} \mathrm{OH}$. At the same time, we have also shown how the binding free energies are overestimated in the $\mathrm{CH}_{4}$ reduction reaction when the effect of solvation is not considered, thus resulting in higher limiting potentials. The addition of the solvation effect to the $\mathrm{CH}_{4}$ reduction pathway has minimized the limiting potential by $\sim 0.75 \mathrm{~V}$. In our catalyst system, $\mathrm{CO}_{2}$ can reduce to $\mathrm{CH}_{4}$ with an overpotential of $0.67 \mathrm{~V}$ and to $\mathrm{CH}_{3} \mathrm{OH}$ at higher negative potentials, i.e., with an overpotential of $1.81 \mathrm{~V}$. We have also qualitatively compared results from current work with the work of Wannakao $\mathrm{S}$. et al. and explained the effect of adsorbate coverage in determining the energetics of $\mathrm{CO}_{2}$ reduction reaction. Furthermore, we have compared the binding free energies of $\mathrm{H}^{*}$ and $\mathrm{CO}^{*}$ to explain that HER is possible along the $\mathrm{CO}_{2} \mathrm{RR}$, but at higher applied negative potentials, our catalyst system suppresses HER thus promoting $\mathrm{CO}_{2}$ reduction to $\mathrm{CH}_{4}$. Future work needs to focus on two main tasks: (i) further studies on $\mathrm{CO}_{2}$ reduction to $\mathrm{C}_{2}$ products and (ii) improving the efficiency of current catalyst system by further minimizing the reduction potential. This can be achieved by introducing catalytically active dopants, thereby tuning the electronic structure properties or by varying the WC nanoparticle size and interaction with the graphene support. Both these tasks are currently the subject of consideration for future work to build on the results from this manuscript.

Supplementary Materials: The following are available online at http://www.mdpi.com/2073-4344/9/7/604/s1.

Author Contributions: S.A was responsible for running majority of calculations, majority of data analysis, and majority of writing. Z.S initiated the first DFT calculations that led to the total scope of the research in this manuscript. R.B.R was responsible for creating graphics in S.I, reviewing and editing the manuscript 
before submission, and conceiving the research project and mentoring the students involved in the research in this manuscript.

Funding: This research received no external funding.

Acknowledgments: R.B.R. gratefully acknowledges financial and research support from the Department of Chemical Engineering at Villanova University through his startup package fund. Z.S. acknowledges support from Villanova University through the VURF summer program. S.A. acknowledges financial support from the Department of Chemical Engineering and the College of Engineering at Villanova University as well.

Conflicts of Interest: The authors declare no conflict of interest. The funders had no role in the design of the study; in the collection, analyses, or interpretation of data; in the writing of the manuscript, or in the decision to publish the results.

\section{References}

1. Yang, Y.; Ajmal, S.; Zheng, X.; Zhang, L. Efficient nanomaterials for harvesting clean fuels from electrochemical and photoelectrochemical $\mathrm{CO}_{2}$ reduction. Sustain. Energy Fuels 2018, 2, 510-537. [CrossRef]

2. Tu, W.; Zhou, Y.; Zou, Z. Photocatalytic Conversion of $\mathrm{CO}_{2}$ into Renewable Hydrocarbon Fuels: State-of-the-Art Accomplishment, Challenges, and Prospects. Adv. Mater 2014, 26, 4607-4626. [CrossRef] [PubMed]

3. Wu, J.; Huang, Y.; Ye, W.; Li, Y. $\mathrm{CO}_{2}$ reduction: From the electrochemical to photochemical approach. Adv. Sci. 2017, 4, 1700194. [CrossRef] [PubMed]

4. Kudo, A.; Miseki, Y. Heterogeneous photocatalyst materials for water splitting. Chem. Soc. Rev. 2009, 38, 253-278. [CrossRef] [PubMed]

5. Liu, Q.; Zhou, Y.; Tian, Z.; Chen, X.; Gao, J.; Zou, Z. $\mathrm{Zn}_{2} \mathrm{GeO}_{4}$ crystal splitting toward sheaf-like, hyperbranched nanostructures and photocatalytic reduction of $\mathrm{CO}_{2}$ into $\mathrm{CH}$ under visible light after nitridation. J. Mater. Chem. 2012, 22, 2033-2038. [CrossRef]

6. Indrakanti, V.P.; Kubicki, J.D.; Schobert, H.H. Photoinduced activation of $\mathrm{CO}_{2}$ on Ti-based heterogeneous catalysts: Current state, chemical physics-based insights and outlook. Energy Environ. Sci. 2009, 2, 745-758. [CrossRef]

7. Indrakanti, V.P.; Schobert, H.H.; Kubicki, J.D. Quantum mechanical modeling of $\mathrm{CO}_{2}$ interactions with irradiated stoichiometric and oxygen-deficient anatase $\mathrm{TiO}_{2}$ surfaces: Implications for the photocatalytic reduction of $\mathrm{CO}_{2}$. Energy Fuels 2009, 23, 5247-5256. [CrossRef]

8. Yan, S.; Wan, L.; Li, Z.; Zou, Z. Facile temperature-controlled synthesis of hexagonal $\mathrm{Zn}_{2} \mathrm{GeO}_{4}$ nanorods with different aspect ratios toward improved photocatalytic activity for overall water splitting and photoreduction of $\mathrm{CO}_{2}$. Chem. Commun. 2011, 47, 5632-5634. [CrossRef]

9. Chen, X.; Li, C.; Grätzel, M.; Kostecki, R.; Mao, S.S. Nanomaterials for renewable energy production and storage. Chem. Soc. Rev. 2012, 41, 7909-7937. [CrossRef]

10. Anpo, M.; Yamashita, H.; Ichihashi, Y.; Fujii, Y.; Honda, M. Photocatalytic reduction of $\mathrm{CO}_{2}$ with $\mathrm{H}_{2} \mathrm{O}$ on titanium oxides anchored within micropores of zeolites: Effects of the structure of the active sites and the addition of Pt. J. Phys. Chem. B 1997, 101, 2632-2636. [CrossRef]

11. Tong, H.; Ouyang, S.; Bi, Y.; Umezawa, N.; Oshikiri, M.; Ye, J. Nano-photocatalytic materials: Possibilities and challenges. Adv. Mater. 2012, 24, 229-251. [CrossRef] [PubMed]

12. Hori, Y.; Kikuchi, K.; Suzuki, S. Production of $\mathrm{CO}$ and $\mathrm{CH}_{4}$ in electrochemical reduction of $\mathrm{CO}_{2}$ at metal electrodes in aqueous hydrogencarbonate solution. Chem. Lett. 1985, 14, 1695-1698. [CrossRef]

13. Kuhl, K.P.; Cave, E.R.; Abram, D.N.; Jaramillo, T.F. New insights into the electrochemical reduction of carbon dioxide on metallic copper surfaces. Energy Environ. Sci. 2012, 5, 7050-7059. [CrossRef]

14. Gonçalves, M.R.; Gomes, A.; Condeço, J.; Fernandes, R.; Pardal, T.; Sequeira, C.A.C.; Branco, J.B. Selective electrochemical conversion of $\mathrm{CO}_{2}$ to $\mathrm{C}_{2}$ hydrocarbons. Energy Convers. Manag. 2010, 51, 30-32. [CrossRef]

15. Tackett, B.M.; Sheng, W.; Chen, J.G. Opportunities and Challenges in Utilizing Metal-Modified Transition Metal Carbides as Low-Cost Electrocatalysts. Joule 2017, 1, 253-263. [CrossRef]

16. Levy, R.B.; Boudart, M. Platinum-like behavior of tungsten carbide in surface catalysis. Science 1973, 181, 547-549. [CrossRef] [PubMed]

17. Zhong, Y.; Xia, X.; Shi, F.; Zhan, J.; Tu, J.; Fan, H.J. Transition metal carbides and nitrides in energy storage and conversion. Adv. Sci. 2016, 3, 1500286. [CrossRef] 
18. Liang, C.; Ying, P.; Li, C. Nanostructured $\beta$-Mo2C Prepared by Carbothermal Hydrogen Reduction on Ultrahigh Surface Area Carbon Material. Chem. Mater. 2002, 14, 3148-3151. [CrossRef]

19. Michalsky, R.; Zhang, Y.J.; Medford, A.J.; Peterson, A.A. Departures from the Adsorption Energy Scaling Relations for Metal Carbide Catalysts. J. Phys. Chem. C 2014, 118, 13026-13034. [CrossRef]

20. Wannakao, S.; Artrith, N.; Limtrakul, J.; Kolpak, A.M. Engineering Transition-Metal-Coated Tungsten Carbides for Efficient and Selective Electrochemical Reduction of $\mathrm{CO}_{2}$ to Methane. ChemSusChem 2015, 8, 2745-2751. [CrossRef]

21. Cheng, J.; Hu, P.; Ellis, P.; French, S.; Kelly, G.; Lok, C.M. Density functional theory study of iron and cobalt carbides for Fischer- Tropsch synthesis. J. Phys. Chem. C 2009, 114, 1085-1093. [CrossRef]

22. Stottlemyer, A.L.; Weigert, E.C.; Chen, J.G. Tungsten Carbides as Alternative Electrocatalysts: From Surface Science Studies to Fuel Cell Evaluation. Ind. Eng. Chem. Res. 2011, 50, 16-22. [CrossRef]

23. Hunt, S.T.; Kokumai, T.M.; Zanchet, D.; Román-Leshkov, Y. Alloying tungsten carbide nanoparticles with tantalum: Impact on electrochemical oxidation resistance and hydrogen evolution activity. J. Phys. Chem. C 2015, 24, 13691-13699. [CrossRef]

24. Hunt, S.T.; Milina, M.; Alba-Rubio, A.C.; Hendon, C.H.; Dumesic, J.A.; Román-Leshkov, Y. Self-assembly of noble metal monolayers on transition metal carbide nanoparticle catalysts. Science 2016, 352, 974-978. [CrossRef] [PubMed]

25. Obradović, M.D.; Gojković, S.L.; Elezović, N.R.; Ercius, P.; Radmilović, V.R.; Vračar, L.D.; Krstajić, N.V. The kinetics of the hydrogen oxidation reaction on WC/Pt catalyst with low content of Pt nano-particles. J. Electroanal. Chem. 2012, 671, 24-32. [CrossRef]

26. Esposito, D.V.; Hunt, S.T.; Kimmel, Y.C.; Chen, J.G. A New Class of Electrocatalysts for Hydrogen Production from Water Electrolysis: Metal Monolayers Supported on Low-Cost Transition Metal Carbides. J. Am. Chem. Soc. 2012, 134, 3025-3033. [CrossRef] [PubMed]

27. Wannakao, S.; Artrith, N.; Limtrakul, J.; Kolpak, A.M. Catalytic Activity and Product Selectivity Trends for Carbon Dioxide Electroreduction on Transition Metal-Coated Tungsten Carbides. J. Phys. Chem. C 2017, 121, 20306-20314. [CrossRef]

28. Chhina, H.; Campbell, S.; Kesler, O. Thermal and electrochemical stability of tungsten carbide catalyst supports. J. Power Sources 2007, 164, 431-440. [CrossRef]

29. Liu, Y.; Kelly, T.G.; Chen, J.G.; Mustain, W.E. Metal carbides as alternative electrocatalyst supports. ACS Catal. 2013, 3, 1184-1194. [CrossRef] [PubMed]

30. Wang, L.; Li, M.; Huang, Z.; Li, Y.; Qi, S.; Yi, C.; Yang, B. Ni-WC/C nanocluster catalysts for urea electrooxidation. J. Power Sources 2014, 264, 282-289. [CrossRef]

31. Antolini, E. Graphene as a new carbon support for low-temperature fuel cell catalysts. Appl. Catal. B Environ. 2012, 123, 52-68. [CrossRef]

32. Ross, P.N., Jr.; Stonehart, P. The relation of surface structure to the electrocatalytic activity of tungsten carbide. J. Catal. 1977, 48, 42-59. [CrossRef]

33. Ooka, H.; Figueiredo, M.C.; Koper, M.T. Competition between hydrogen evolution and carbon dioxide reduction on copper electrodes in mildly acidic media. Langmuir 2017, 33, 9307-9313. [CrossRef] [PubMed]

34. MedeA, M. Exploration and Design Analysis; Materials Design Inc.: New York, NY, USA, 2016.

35. Kresse, G.; Furthmüller, J. Software VASP, vienna. Rev. B 1996, 54, 169.

36. Hafner, J. Ab-initio simulations of materials using VASP: Density-functional theory and beyond. J. Comput. Chem. 2008, 29, 2044-2078. [CrossRef] [PubMed]

37. Kresse, G.; Furthmüller, J. Efficient iterative schemes for ab initio total-energy calculations using a plane-wave basis set. Phys. Rev. B 1996, 54, 11169-11186. [CrossRef] [PubMed]

38. Piotrowski, M.J.; Ungureanu, C.G.; Tereshchuk, P.; Batista, K.E.; Chaves, A.S.; Guedes-Sobrinho, D.; Da Silva, J.L. Theoretical Study of the Structural, Energetic, and Electronic Properties of 55-Atom Metal Nanoclusters: A DFT Investigation within van der Waals Corrections, Spin-Orbit Coupling, and PBE+U of 42 Metal Systems. J. Phys. Chem. C 2016, 120, 28844-28856. [CrossRef]

39. Bucko, T.; Hafner, J.; Lebegue, S.; Angyán, J.G. Improved Description of the Structure of Molecular and Layered Crystals: Ab Initio DFT Calculations with van der Waals Corrections. J. Phys. Chem. A 2010, 114, 11814-11824. [CrossRef]

40. Klimeš, J.; Michaelides, A. Perspective: Advances and challenges in treating van der Waals dispersion forces in density functional theory. J. Chem. Phys. 2012, 137, 120901. [CrossRef] 
41. Watson, G.W.; Wells, R.P.K.; Willock, D.J.; Hutchings, G.J. $\pi$ adsorption of ethene on to the $\{111\}$ surface of copper: A periodic ab initio study of the effect of k-point sampling on the energy, atomic and electronic structure. Surf. Sci. 2000, 459, 93-103. [CrossRef]

42. Peterson, A.A.; Abild-Pedersen, F.; Studt, F.; Rossmeisl, J.; Nørskov, J.K. How copper catalyzes the electroreduction of carbon dioxide into hydrocarbon fuels. Energy Environ. Sci. 2010, 3, 1311-1315. [CrossRef]

43. Nørskov, J.K.; Rossmeisl, J.; Logadottir, A.; Lindqvist, L.R.K.J.; Kitchin, J.R.; Bligaard, T.; Jonsson, H. Origin of the Overpotential for Oxygen Reduction at a Fuel-Cell Cathode. J. Phys. Chem. B 2004, 108, 17886-17892. [CrossRef]

44. Yoo, J.S.; Christensen, R.; Vegge, T.; Nørskov, J.K.; Studt, F. Theoretical Insight into the Trends that Guide the Electrochemical Reduction of Carbon Dioxide to Formic Acid. ChemSusChem 2016, 9, 358-363. [CrossRef] [PubMed]

45. Kuhl, K.P.; Hatsukade, T.; Cave, E.R.; Abram, D.N.; Kibsgaard, J.; Jaramillo, T.F. Electrocatalytic Conversion of Carbon Dioxide to Methane and Methanol on Transition Metal Surfaces. J. Am. Chem. Soc. 2014, 136, 14107-14113. [CrossRef] [PubMed]

46. Hirunsit, P. Electroreduction of Carbon Dioxide to Methane on Copper, Copper-Silver, and Copper-Gold Catalysts: A DFT Study. J. Phys. Chem. C 2013, 117, 8262-8268. [CrossRef]

47. Roux, B.; Simonson, T. Implicit solvent models. Biophys. Chem. 1999, 78, 1-20. [CrossRef]

48. Cramer, C.J.; Truhlar, D.G. Implicit solvation models: Equilibria, structure, spectra, and dynamics. Chem. Rev. 1999, 99, 2161-2600. [CrossRef] [PubMed]

(C) 2019 by the authors. Licensee MDPI, Basel, Switzerland. This article is an open access article distributed under the terms and conditions of the Creative Commons Attribution (CC BY) license (http://creativecommons.org/licenses/by/4.0/). 